\title{
Prediction of the thermal decomposition of organic peroxides by validated QSPR models
}

\author{
Vinca Prana ${ }^{\mathrm{a}, \mathrm{b}}$, Patricia Rotureau, ${ }^{\mathrm{b}, *}$, Guillaume Fayet ${ }^{\mathrm{b}}$, David Andréc ${ }^{\mathrm{c}}$, Serge $\operatorname{Hub}^{\mathrm{c}}$, Patricia \\ Vicot $^{\mathrm{b}}$, Li Rao ${ }^{\mathrm{a}}$ and Carlo Adamo ${ }^{\mathrm{a}, \mathrm{d}}$ \\ ${ }^{a}$ Institut de Recherche de Chimie Paris, Chimie ParisTech CNRS, 11 rue P. et M. Curie, \\ 75005 Paris, France \\ ${ }^{\mathrm{b}}$ Institut National de l'Environnement Industriel et des Risques (INERIS), Parc \\ Technologique Alata, BP2, 60550 Verneuil-en-Halatte, France \\ c ARKEMA, rue Henri Moissan, BP63, 69493 Pierre Benite, France \\ d Institut Universitaire de France, 103 Boulevard Saint Michel, F-75005 Paris, France`
}

\begin{abstract}
Organic peroxides are unstable chemicals which can easily decompose and may lead to explosion. Such a process can be characterized by physico-chemical parameters such as heat and temperature of decomposition, whose determination is crucial to manage related hazards. These thermal stability properties are also required within many regulatory frameworks related to chemicals in order to assess their hazardous properties. In this work, new quantitative structure-property relationships (QSPR) models were developed to predict accurately the thermal stability of organic peroxides from their molecular structure respecting the OECD guidelines for regulatory acceptability of QSPRs. Based on the acquisition of 38 reference experimental data using DSC (differential scanning calorimetry) apparatus in homogenous experimental conditions, multi-linear models were derived for the prediction of the decomposition heat and the onset temperature using different types of molecular descriptors. Models were tested by internal and external validation tests and their applicability domains were defined and analyzed. Being rigorously validated, they presented the best performances in terms of fitting, robustness and predictive power and the descriptors used in these models were linked to the peroxide bond whose breaking represents the main decomposition mechanism of organic peroxides.
\end{abstract}

Keywords: thermal stability; QSPR; organic peroxides; OECD principles; REACH regulation *Corresponding author: tel.: + 33(0)344556329; fax: + 33(0)344556565

E-mail address: patricia.rotureau@ineris.fr 


\section{Introduction}

Organic peroxides are reactive compounds, containing the -O-O- bond [1-2], that can be formed naturally by auto-oxidation with oxygen in certain solvents, such as diethylether. They can lead to highly explosive peroxidic residues, requiring specific safety precautions, like addition of oxidation inhibitors to prevent the formation of undesirable organic peroxides [36]. Organic peroxides are more or less stable due to a relatively low -O-O- bond energy (20$50 \mathrm{kcal} / \mathrm{mol}$ ) [7]. Since they generate instable radicals during their decomposition, organic peroxides are commonly used as catalyst and as radical polymerization initiators. The decomposition of organic peroxides can nevertheless be dangerous and can lead to serious effects [8-10]. To reduce the risk of incidents and of accidents, their hazards are intensively studied. In order to avoid the accidents by the customers and users, the organic peroxide producers provide information concerning the properties of commercial organic peroxides and give recommendations for safe handling and use of organic peroxides [11-12]. General documents also describe the characteristics of organic peroxides and the safety rules to apply to safely handle them at laboratory scale [3].

Concerning the regulations, organic peroxides belong to a dedicated division (Division 5.2), as described in the UN Dangerous Goods Transportation Recommendations [13], or in GHS (Globally Harmonized System of classification and labelling of chemicals) [14] with 7 different classes (types A to $G$ ) related to their hazardous potential and leading to different amounts authorized for transport.

The decomposition of organic peroxides can be triggered and accelerated by heat, mechanical shock or friction and by various contaminants [15-16]. To produce, transport and provide safely the numerous organic peroxides, the industry generally commercializes them in low concentration diluted in variable solvents.

In order to improve and homogenize the knowledge of the marketed chemicals, the European Union regulation REACH (Registration, Evaluation, Authorization and Restriction of Chemicals) [17-18] requires the evaluation of physico-chemical, toxicological and ecotoxicological properties for all chemicals produced or imported by more than one ton by year in Europe. To help industry to meet the requirements of REACH regulation as far as the chemical safety assessment is concerned, ECHA technical guidances have been published [19-20] and a general testing strategy for physico-chemical properties was proposed to consider the order of testing.

As far as organic peroxides are concerned, even if they belong to a dedicated regulated division or class, the knowledge of their explosive properties, as defined by the UN 
recommended tests [21], is of great importance. As entry data, their thermal stability (represented by the energy and temperature of decomposition) is a key property that is considered as a pre-selection criterion to identify substances that could undergo explosive reactions. So, it is used in the complex procedure of classification of explosives and organic peroxides [21]. Indeed, the UN regulation indicates that there is no need to perform this complex procedure when the decomposition heat (corresponding to the amount of energy released during the decomposition) is lower than $500 \mathrm{~J} / \mathrm{g}$. Measured by calorimetric analyses, notably by differential scanning calorimetry (DSC), the decomposition heat is estimated with measurement uncertainties of about 5-10\% [22,23] and less than $5^{\circ} \mathrm{C}$ for the onset temperature [23].

For safety reasons but also for technical reasons, experimental tests can be difficult to implement for unstable substances like organic peroxides. As a consequence, the development of methods used for the prediction of data can be of great help at the research and development step and can help to accelerate and fulfil the next registration deadlines. As a simple prediction tool of reactivity hazards, the CHETAH software based on Benson's group contribution method was developed by ASTM [24]. Considering only six organic peroxides, Mohan et al. [25] demonstrated some correlations between CHETAH criteria (oxygen balance, the maximum decomposition heat, the difference between heat of combustion and decomposition heat) and explosive properties. In one recent study, Sato et al. [26] showed that there is a mutual correlation between CHETAH criteria and the explosibility of self-reactive substances except for organic peroxides and azo compounds. Nevertheless, it has to be noticed that the CHETAH software provides the maximum decomposition heat (considering that the available oxygen first oxidizes hydrogen to water and then carbon to carbon dioxide) and not the actual experimental decomposition heat.

Considering the REACH regulatory framework, Lewis et al. [27] advocated the use of powerful computer-aided $a b$ initio techniques to generate predictions of key properties of broad classes of chemicals, without resorting to costly experimentation and potentially hazardous testing. Among these alternative methods to experimental testing, Quantitative Structure-Activity/Property Relationships (QSAR/QSPR) were clearly recommended in REACH and in technical guidances $[19,20]$ to obtain information data. Indeed, they represent powerful tools of prediction [28] used more and more for physico-chemical applications [2930]. Their applicability in an industrial context was also recently demonstrated by Patlewicz et al. [31]. To support the development and use of QSPRs, OECD drawn up 5 principles for the validation of QSAR/QSPR models for regulatory purpose [32]. 
Some recent reviews [33-34] list the existing predictive models developed for the relevant properties of chemicals in the context of REACH. In particular, Dearden et al. [34] focused on the validation of models dedicated to physico-chemical properties according to OECD principles to favor the use of predicted property values in submissions to the European Chemicals Agency (ECHA).

Considering the prediction of thermal stability, some models exist for different families of compounds like nitroaromatic compounds [35-39], nitramines [40-42], ionic liquids [43] or polymers [44]. Nevertheless, to our knowledge, only one reference exists [45] to predict the reactivity hazards of organic peroxides using the QSPR approach. In this study, a limited database of 16 organic peroxides was used to derive models with no validation set, neither definition of applicability domain. Therefore, the robustness and the predictivity of these models must be at least validated and may be improved.

Consequently, the aim of this paper was to develop new robust QSPR models respecting OECD principles dedicated to the prediction of the heat and temperature of decomposition. To achieve this goal and considering that no large database exists in literature for organic peroxides (only 16 and 9 DSC data from the works of Lu et al. [45] and Ando et al. [22] respectively), an experimental database of 38 organic peroxides was built for these properties obtained in homogenous experimental conditions using DSC. The amount and quality of experimental data allowed to performing both internal and external validation methods to ensure the good performances of the multi-linear regression (MLR) models developed and then reach more robust and accurate models than the ones proposed by Lu et al..

Besides, the approach combined QSPR methodology with quantum chemical descriptors obtained with density functional theory (DFT) calculations. Indeed, a better chemical interpretation of the developed models can be expected using this type of descriptors as already demonstrated in previous works for nitro compounds [46-48]. To our knowledge, this work leads to the first completely validated QSPR models (including the definition of applicability domains) dedicated to the prediction of the thermal stability of organic peroxides.

\section{Experimental details}

\subsection{Construction of the database}

As mentioned above, the first work carried out on the prediction of thermal stability of organic peroxides [45] was based on only 16 samples. The concentration of the peroxides 
used ranged between 34\% and 98\% wt [45], with no indication of the dilution solvent or of the possible contaminants or co-products present in the samples.

In this study, to limit or even avoid any effect of the poor purity of organic peroxide samples, the origin of the organic peroxide samples was taken into account with great care. The following rules of organic peroxides selection were followed:

- choice among the commercial organic peroxides, with a perfect knowledge of their composition;

- choice of the highest purities and concentrations available for the organic peroxides;

- elimination of organic peroxides available as mixtures.

For example, the 2-butanone peroxide also known in industries as the methyl ethyl ketone peroxide (MEKPO) was discarded since several isomers exist [49].

Using these criteria, 38 organic peroxide samples were selected (see Table 1 for the different kind of organic peroxides families and Table 2 for the list and concentrations), 31 provided by Arkema and 7 by Akzo Nobel. The concentrations were close to 97-99\% (weight of organic peroxide divided by weigh of samples) exception given for some of them whose containing inert solvents (water, organic solvent or an inert inorganic). The size of the dataset was notably limited to organic peroxides available with no transportation, handling and storage issues.

\subsection{Experimental dataset and methods}

The experimental data were collected from calorimetric tests completed on the 38 selected organic peroxides. These tests were carried out on two different calorimeters with crosschecking, indicating that the results obtained were not equipment-dependent, and were within the precision limits of the DSC method recommended in ASTM E537-2 [23]. The calorimetric tests were performed using DSC131 from SETARAM and with DSC821e from Mettler-Toledo, with a scanning rate of $5 \mathrm{~K} / \mathrm{min}$ from ambient temperature to $300^{\circ} \mathrm{C}$. A few milligram sample was introduced, at ambient temperature, into a closed stainless steel crucible. The DSC vessels were previously washed, passivated, rinsed and dried. Each sample was tested three times to establish good reproducibility. The onset temperature was defined as the extrapolated onset temperature (see Figure 1) following ASTM E537-2 [23].

In order to consider concentration effects, three organic peroxide samples (one dialkyl peroxide and two peroxyesters) were diluted with an inert solvent (type A solvent according 
to actual regulation with boiling point close to $175^{\circ} \mathrm{C}$ ) to obtain different concentrations from $7 \%$ up to $99 \%$ wt (see Figure 2).

\section{Computational details}

\subsection{Partitioning of the dataset}

The considered dataset of 38 organic peroxides was divided into a training set, containing two thirds of the molecules of the dataset and a validation set constituted by the remaining molecules. This partition enabled both sets to be of sufficient size with similar distributions to allow a robust development and an external validation of models. The partitioning of the dataset was also visually inspected to ensure that the validation set covered at best the chemical diversity of the domain of applicability of the model, i.e. of the molecules in the training set. The range of the property values was also checked in order to prevent that no data was out of the general range of values in the dataset and could influence too much the correlation. For example, the decomposition heat of the 2,5-dimethyl-2,5-dihydroperoxy hexane was too high compared to the values of other peroxides. So, this compound was considered as outlier and removed for the prediction of this property (see Figure S1). For the onset temperature, the 3,3,5,7,7-pentamethyl-1,2,4-trioxepane was also considered as outlier and removed for the same reason (see Figure S2) coupled by the fact that such type of cyclic organic peroxide was not well represented in terms of chemical structures in the dataset. So, in both cases, a training set of 25 compounds was used for the development and the internal validation of models, while a validation set of 12 compounds was considered for external validation to evaluate their predictive power.

\subsection{Molecular structure calculation}

A preliminary conformation analysis was carried out with Scigress software [50] using the Conflex algorithm [51,52] and the MM3 force field [53]. The most stable conformer was optimized again with Gaussian09 software [54] using DFT calculations with the PBE0 [55] functional and the $6-31+G(d, p)$ basis set. This functional provides results close to those provided by the most-common B3LYP approach, but being parameter-free, is more physically sound [55]. Vibrational frequencies were then computed to ensure that all final stable conformations exhibited no imaginary frequency.

\subsection{Molecular descriptor calculation}


Each molecular structure was then characterized by a series of descriptors (constitutional, topological, geometric and quantum chemical) [56, 57]. Most of them were calculated using the CodessaPro software [58] but additional descriptors were taken into account considering the specific case of organic peroxides and their reactivity. As proposed by Lu [45], the concentration of the organic peroxide was also chosen as a descriptor potentially influencing the temperature of decomposition of organic peroxides. Other descriptors were considered as explained in a previous work [35], notably the oxygen balance [21,59] which is an empirical descriptor well known to evaluate hazards related to energetic materials. Some more specific descriptors to the peroxide functional group were computed such as the number of peroxide bonds $\left(\mathrm{n}_{\mathrm{OO}}\right)$, the OOR angle, the charge on oxygen atoms (Qoo) or the distance between these atoms $\left(\mathrm{d}_{\mathrm{OO}}\right)$ to better describe the decomposition process. As the cleavage of the -O-O- bond is considered as the first step in the decomposition process of organic peroxides $[7,60]$, the dissociation energy $\left(E_{\text {disso }}\right)$ of the peroxide bond was also calculated. When several peroxide functional groups were present in the molecule, the one presenting the lowest dissociation energy was considered for the calculation of all descriptors related to the -O-O- bond. Moreover, descriptors arising from conceptual DFT [61,62], already successfully used in QSPR models for the prediction of the decomposition heat of explosives [35,36,46] or organic peroxides [45], were considered. In particular, descriptors related to the peroxide bond properties were developed and used in this work such as the local Fukui function $\mathrm{f}$ [61-63]:

$$
f_{A}^{+}=q_{A}(N+1)-q_{A}(N) ; f_{A}^{-}=q_{A}(N)-q_{A}(N-1)(1)
$$

where $f_{A}^{+}$and $f_{A}^{-}$are positive and negative Fukui functions and $q_{A}$ is the atomic charge of atom $A$ in the molecule containing in the molecule ( $\mathrm{N}$ electrons), its anion ( $\mathrm{N}+1$ electrons) and cation $(\mathrm{N}-1)$.

Other descriptors include hardness:

$$
\eta=\frac{(I P-E A)}{2}
$$

where IP and EA are the ionization potential and the electron affinity and local softness:

$$
S_{A}^{x}=\frac{f_{A}}{\eta}=\frac{f_{A}(I P-E A)}{2}
$$

where $\mathrm{x}$ can be + or -. Usually IP and EA are approximated by the energies of the Highest Occupied Molecular Orbital (HOMO) and by the Lowest Unoccupied Molecular Orbital (LUMO) (see references 61 and 62 for more details). 


\subsection{Model building and performances}

All models were developed on the training set based on multi-linear regressions (MLR) using the Best Multi Linear Regression (BMLR) [57] approach as implemented in CodessaPro program. The final model was chosen as the best compromise between correlation and number of descriptors as explained in previous works [35].

To evaluate the performances of models, a series of internal and external validations were computed. The goodness of fit was measured by the determination coefficient $\left(\mathrm{R}^{2}\right)$, the mean absolute error (MAE) and the root mean square error (RMSE) between predicted and experimental values. The $\mathrm{Q}^{2}$ coefficients issued from both leave-one-out (LOO) and leavemany-out (LMO) cross validations measured the robustness of the model, i.e. the dependence of the fitting of the model to any molecule(s) of the training set via the $\mathrm{Q}^{2}{ }_{\mathrm{LOO}}, \mathrm{Q}^{2}{ }_{5 \mathrm{CV}}, \mathrm{Q}^{2}{ }_{10 \mathrm{CV}}$, $\mathrm{Q}^{2}{ }_{7 \mathrm{CV}}$ coefficients (for LOO, 5-fold, 10-fold and 7-fold cross validations, respectively). Robust models are expected to present a low difference between $\mathrm{Q}^{2}$ and $\mathrm{R}^{2}$ coefficients. It has to be noticed that cross validation does not measure the predictivity of models because the set of molecules excluded at each step of the cross validation procedure and then used to calculate $\mathrm{Q}^{2}$ has already been used for the building of the model $[64,65]$. Besides, to ensure that models did not correspond to chance correlations, a Y-scrambling test was realized on the training set. Random permutations of experimental property values were performed (1000 iterations) and new models were recalculated [66]. To evaluate the impact of randomization, average and standard deviation in $\mathrm{R}^{2}$ random coefficients were calculated $\left(\mathrm{R}^{2}\right.$ YS and $\left.\mathrm{SD}_{\mathrm{YS}}\right)$. Low $\mathrm{R}^{2}$ ys values are expected to avoid chance correlation. To go further, Rücker proposed that the difference between $\mathrm{R}^{2}$ of the original model and $\mathrm{R}^{2} \mathrm{Ys}$ should be roughly superior or equal to $2.3 \mathrm{SD}_{\text {Ys }}$ to ensure a statistical significance at a $1 \%$ level and superior or equal to $3 \mathrm{SD}_{\mathrm{Ys}}$ at a $0.1 \%$ level [67].

The predictive power of models was measured on the validation set based on the same coefficients $\left(\mathrm{R}_{\text {ext }}^{2}, \mathrm{RMSE}_{\mathrm{ext}}, \mathrm{MAE}_{\mathrm{ext}}\right)$ as those used for the fitting. Several additional external validation coefficients proposed in literature were calculated as: $\mathrm{Q}^{2} \mathrm{~F} 1$ proposed by Tropsha [68] and the OECD guidance document [32], $\mathrm{Q}^{2}$ F2 defined by Schuurman [69], $\mathrm{Q}^{2} \mathrm{~F}$ by Consonni [70] and CCC by Lin [71,72].

Considering that a QSPR model only offers reliable predictions for compounds similar to those belonging to the training data set, the applicability domain [73,74] required by the $3^{\text {rd }}$ OECD point, was determined based on the descriptors included in the model. Euclidean distance method available in Ambit discovery software [75] was used with a 95\% threshold, i.e. the domain was calculated to contain $95 \%$ of the molecules of the training set. Then, the 
predictivity inside the applicability domain was calculated based on the molecules of the validation set belonging to this domain. Corresponding coefficients for external validation were denoted $\mathrm{R}_{\mathrm{in}}$, RMSE $\mathrm{E}_{\mathrm{in}}, \mathrm{MAE}_{\mathrm{in}}, \mathrm{Q}^{2} \mathrm{~F} 1 \mathrm{in}, \mathrm{Q}^{2} \mathrm{~F} 2 \mathrm{in}, \mathrm{Q}^{2} \mathrm{F3in}$ and $\mathrm{CCC}_{\mathrm{in}}$.

\section{Results and discussion}

\subsection{DSC results}

The reactivity data of organic peroxides are shown in Tables 2 and 3 . The ranges of detected onset temperature $\left(53-180^{\circ} \mathrm{C}\right)$ and decomposition heat $(441-2622 \mathrm{~J} / \mathrm{g})$ cover most of the commercial grade of organic peroxides. One example of DSC curve is given in Figure 1. The concentration effect on the decomposition heat measured by unit mass of tested sample is linear in the range of the tested concentrations for the three tested organic peroxides (Figure 2). That confirmed that the solvent did not contribute to the decomposition energy and that the models can be simplified from the concentration effect to only take into account the pure organic peroxides.

\subsection{Use of existing models}

QSPR models were developed by Lu and Mannan [45] for the heat and temperature of decomposition from a dataset of 16 organic peroxides. Even if these models presented good performances in terms of fitting $\left(\mathrm{R}^{2}\right)$, they failed in robustness $\left(\mathrm{Q}^{2}\right)$, in particular for the prediction of the onset temperature using $M L R\left(Q^{2}=0.108\right)$. Due to the low number of organic peroxides available in this study, models were not validated with an external set of molecules and their applicability domains were not defined. In a first step, 24 organic peroxides from our experimental database, different from the 16 molecules of the training set used by Lu, were computed on these MLR models (for both heat and temperature of decomposition) to perform an external validation and estimate their predictive power. The proposed model for the decomposition heat was not predictive considering $\mathrm{R}^{2}{ }_{\mathrm{ext}}=0.06, \mathrm{RMSE}_{\mathrm{ext}}=250 \mathrm{kcal} / \mathrm{mol}$ and $\mathrm{MAE}_{\text {ext }}=149 \mathrm{kcal} / \mathrm{mol}$. The model developed for the prediction of the onset temperature was slightly better with $\mathrm{R}^{2}$ ext equal to 0.67 but was still not predictive with $\mathrm{RMSE}_{\mathrm{ext}}=67^{\circ} \mathrm{C}$ and $\mathrm{MAE}_{\mathrm{ext}}=57^{\circ} \mathrm{C}$. In the following, QSPR models were developed for these two reactivity properties from our experimental database of 38 organic peroxides allowing a complete validation.

\subsection{Multi-linear regressions for the decomposition heat}


From more than 300 calculated descriptors, a first model was developed for the decomposition heat $(\Delta \mathrm{H}$ in $\mathrm{J} / \mathrm{g})$ using the BMLR method. Considering the best compromise between the correlation and the number of descriptors, a four-parameter model was obtained:

$\Delta \mathrm{H}=-874 \mathrm{C}+3359 \mathrm{Qoo}, \mathrm{nbo}+366 \mathrm{~S}_{\mathrm{OO}}^{-}+87 \mathrm{~S}_{\mathrm{rot}}-2475$

Where $\mathrm{C}$ is the concentration of the target peroxide (gram of organic peroxide per gram of samples) with a t-test of -4.8, Qoo,nbo is the average NBO charges for an oxygen in the -O-Obond (t-test=-6.0), $\mathrm{S}_{\mathrm{OO}}^{-}$is the local softness on the HOMO orbital of oxygen in the -O-Obond (t-test=6.0) and $\mathrm{S}_{\text {rot }}$ is the rotational entropy at $300 \mathrm{~K}$ (t-test=-3.9).

In this equation, all descriptors present the same importance in the regression with close absolute values of t-test (from 3.9 to 6). The presence of the concentration as descriptor (already evidenced in Lu's work [45]) should be particularly noticed as it mentions the importance of the organic peroxide concentration in the prediction of the decomposition energy. It also confirms that more the concentration is important, more the decomposition enthalpy measured for the tested sample is important (as illustrated in experimental results, section 4.1). Two other descriptors are directly related to the peroxide bond: the local softness and the NBO charges of oxygen which characterize the reactivity of this bond thus confirming the critical role of the dissociation of the -O-O- bond in the decomposition process.

From a statistical point of view, even if the performances were good in terms of fitting with $\mathrm{R}^{2}=0.90, \mathrm{RMSE}=113 \mathrm{~J} / \mathrm{g}, \mathrm{Q}^{2}{ }_{\mathrm{LOO}}=0.83, \mathrm{R}^{2} \mathrm{YS}=0.17, \mathrm{SD}_{\mathrm{YS}}=0.10$, the predictivity was very low with only $\mathrm{R}^{2}{ }_{\mathrm{ext}}=0.32$ and $\mathrm{RMSE} \mathrm{ext}=358 \mathrm{~J} / \mathrm{g}$ (Table 4 ).

In a second step, a QSPR model was developed for the decomposition heat divided by the concentration of the organic peroxide $(\Delta \mathrm{H} / \mathrm{C})$ in order to consider the influence of this parameter. Indeed, $\mathrm{C}$ may be more considered as a dilution effect on $\Delta \mathrm{H}$ (as shown in Figure 2) rather than a linear term in the MLR model contributing in the same way as molecular descriptors. A very interesting model was obtained with 4 parameters (see Table S1):

$\Delta \mathrm{H} / \mathrm{C}=54{ }^{1} \mathrm{~K}-990 \mathrm{n}_{\mathrm{OO}}+12934 \mathrm{~d}_{\mathrm{OO}}+2631 \mathrm{Q}_{\mathrm{OO}}-19371$

Where ${ }^{1} \mathrm{~K}$ is the order 1 Kier shape index (t-test=12.7), $\mathrm{n}_{\mathrm{OO}}$ is the number of peroxide bonds ( $t$-test $=-14.9), d_{O O}$ is the distance between the oxygen atoms of the peroxide bond (t-test $=4.5$ ) and $\mathrm{Q}_{\mathrm{Oo}}$ is the average Mulliken charges of these two $\mathrm{O}$ atoms (t-test=7.8). 
The Kier shape index of first order is a topological index that encodes the number of atoms in the molecule and the relative degree of cyclicity [57,76]. The three other descriptors are linked to the peroxide bond. The most important descriptor (considering the t-test values) is the number of peroxide bonds in the molecule, confirming the accepted mechanism of decomposition of organic peroxides starting by an homolytic cleavage of the -O-O- bond $[7,60]$.

The predicted decomposition heat divided by the concentration using Eq. (5) as a function of experimental values was plotted in Figure 3 (see Table 2 for calculated property values). As illustrated in Table 4, the model was characterized by remarkable correlation $\left(\mathrm{R}^{2}=0.97\right.$, $\mathrm{RMSE}=99 \mathrm{~J} / \mathrm{g})$ and robustness $\left(\mathrm{Q}^{2}{ }_{\mathrm{LOO}}=\mathrm{Q}^{2}{ }_{10 \mathrm{CV}}=\mathrm{Q}^{2}{ }_{7 \mathrm{CV}}=0.94\right.$ and $\left.\mathrm{Q}^{2}{ }_{5 \mathrm{CV}}=0.95\right)$. It did not result from chance correlation, since the models issuing from Y-randomization presented low correlations $\left(\mathrm{R}^{2}{ }_{\mathrm{YS}}=0.17, \mathrm{SD}_{\mathrm{YS}}=0.10\right)$ as shown in Figure 4. Besides, the criterion of Rücker [68] was respected: $\mathrm{R}^{2}-\mathrm{R}^{2} \mathrm{YS}(0.80)$ was higher than $2.3 \mathrm{SD}_{\mathrm{YS}}(0.23)$. Finally, the predictivity for the 12 molecules of the validation set was very good $\left(R^{2}{ }_{\text {ext }}=0.81, R M S E_{\text {ext }}=301 \mathrm{~J} / \mathrm{g}\right.$, $\mathrm{Q}^{2}{ }_{\mathrm{F} 1}=\mathrm{Q}^{2}{ }_{\mathrm{F} 2}=0.74, \mathrm{Q}^{2}{ }_{\mathrm{F} 3}=0.77$ and $\mathrm{CCC}=0.82$ ). For this model, no molecule of the validation set was out of the applicability domain implying that the same performances were obtained considering the applicability domain of the model.

This model was fully validated and presented better performances than the one previously proposed [45]. Indeed, if the coefficients of determination were quite similar $\left(\mathrm{R}^{2}=0.97\right.$ for eq. 5 and $\mathrm{R}^{2}=0.92$ for $\left.\mathrm{Lu}\right)$, this new model presents better robustness $\left(\mathrm{Q}^{2}=0.77\right.$ versus $\mathrm{Q}^{2}=-0.81$ respectively).

\subsection{Multi-linear regressions for the onset temperature}

A MLR model was also developed for the prediction of the onset temperature of decomposition. A three-parameter model (see Table S2) was found to be the best compromise between correlation and number of descriptors among the 8 equations including up to 9 descriptors sorted out by the BMLR method (equation 6) with $\mathrm{R}^{2}=0.84$ and $\mathrm{Q}^{2}=0.77$ (Figure 5).

$\mathrm{T}_{\text {onset }}=144 \mathrm{~F}_{\text {OO }}^{-}+29 \mathrm{n}_{\mathrm{OO}}-20$ gap +194

Where $\mathrm{n}_{\mathrm{OO}}$ is the number of peroxide bonds (t-test=3.6), $\mathrm{F}_{\mathrm{OO}}^{-}$is the average local Fukui function on $\mathrm{O}$ atoms of the peroxide bond (t-test=7.4), gap is the $\mathrm{eV}$ energy difference between the LUMO and HOMO orbitals (t-test=-4.4). This gap, a positive number, is an 
indicator of the stability of the molecule: the larger the gap is, the more stable is the molecule. $\mathrm{F}_{\mathrm{OO}}^{-}$is the Fukui function (quantum chemical descriptor) that characterizes the reactivity and more specifically the electrophilic attack on the peroxide bond. It's worth to note that the dissociation energy did not appear in the model indicating that even if the first step of the decomposition is the cleavage of the homolytic peroxide bond, the decomposition process is also strongly influenced by the reactivity of radicals formed [7,60]. Nevertheless, two descriptors were linked to the peroxide bond: $\mathrm{F}_{\mathrm{OO}}^{-}$and $\mathrm{n}_{\mathrm{OO}}$ confirming again the role of the peroxide bond in the decomposition process. The former was already present in the model for the prediction of the decomposition heat divided by the concentration (eq.5) but for equation 6 , the most important descriptor was $\mathrm{F}^{-}$oo considering the value of the $\mathrm{t}$-test, indicating the importance of quantum chemical descriptors in the prediction of this property.

The determination coefficient was slightly lower than the model of Lu [45] in terms of fitting (0.84 vs. 0.92 ) but the robustness was higher (0.77 instead of 0.108$)$. Excluding the single molecule of the validation set out of the applicability domain (2,5-dimethyl-2,5-di(tertbutylperoxy)hexane), the predictivity inside the $\mathrm{AD}$ was good with $\mathrm{R}^{2}{ }_{\mathrm{in}}=0.83, \mathrm{RMSE}_{\mathrm{in}}=14^{\circ} \mathrm{C}$, $\mathrm{Q}^{2}{ }_{\mathrm{F} 1}=\mathrm{Q}^{2}{ }_{\mathrm{F} 2}=0.78, \mathrm{Q}^{2} \mathrm{~F}=0.83$ and $\mathrm{CCC}=0.90$ (see Table 4).

It is noteworthy that the concentration was not included in the multi-linear equation (as proposed by $\mathrm{Lu}$ [45]), thus indicating that, contrary to the decomposition heat, it does not affect the onset temperature.

\section{Conclusion}

In this study, the largest experimental database including thermal properties for 38 organic peroxides obtained from homogeneous measurements was built to develop and validate the first QSPR models for the prediction of the heat and the onset temperature of decomposition. Considering more than 300 descriptors including quantum chemical ones calculated with the density functional theory, two MLR models presenting high performances were constructed according to all OECD principles for the validation of QSAR/QSPR models for regulatory use. The number and quality of experimental data (principle 1) allowed validating them on a series of internal and external tests (principle 4). A four-parameter model was obtained for the prediction of the decomposition heat divided by the peroxide concentration reaching high performances in terms of fitting, robustness and predictivity $\left(\mathrm{R}^{2}=0.97, \mathrm{Q}^{2}=0.94\right.$ and $\mathrm{R}^{2}{ }_{\text {ext }}=0.81$ ). A three-parameter model presenting also good performances was sorted out $\left(\mathrm{R}^{2}=0.84\right.$ and $\mathrm{Q}^{2}=0.77, \mathrm{R}^{2}{ }_{\mathrm{ext}}=0.80$ ) for the prediction of the onset temperature of decomposition. Algorithms are unambiguous (principle 2) and their applicability domains are 
clearly defined (principle 3). Finally, descriptors included in the models were chemically pertinent (principle 5) such as the number of peroxide bonds in the molecule, the distance between the oxygen of this bond and the charge of these atoms, confirming that the homolytic cleavage of the -O-O- bond is critical in the mechanism of decomposition of organic peroxides. The pertinence of quantum descriptors was also demonstrated to reach high performances in terms of predictivity. These models can now be used to fulfil requirements of REACH regulation or as a first screening tool indicating predicted data related to reactivity hazards in view of development of new organic peroxides.

\section{Acknowledgements}

This work was performed using HPC resources from GENCI-CCRT (Grant 2013t2013086639). The authors thank the ANR (PREDIMOL research project (ANR-10-CDII007) including ARKEMA, Chimie ParisTech, CNRS, IFPEN, INERIS, Materials Design and University Paris Sud 11) for financement, AkzoNobel for providing free organic peroxides samples and ARKEMA Functional Additives Business Unit for providing most of Luperox® samples.

\section{References}

[1] J. Sanchez, T. Myers, Peroxides and Peroxide compounds, Organic peroxides, in: Kirk-Othmer Encyclopedia of Chemical Technology, fourth ed., John Wiley \& Sons, New York, 1996, vol. 18, pp 230-310.

[2] T. Myers, Initiators (Free Radicals), in: Kirk-Othmer Encyclopedia of Chemical Technology, fourth ed., John Wiley \& Sons, New York, 1995, vol. 14, pp 431-460.

[3] J. Lemarquand, J. Triolet, Identification and handling of peroxidisable compounds, cahier de notes documentaires, Hygiène et Sécurité du travail, INRS, ND 2163-186-02 (2002).

[4] D. E. Clark, Peroxides and peroxide-forming compounds, Chem. Health Safe. (2001) $12-22$.

[5] C.S. Sheppard, O.L. Magelli, Organic Peroxides and Peroxy Compounds - General Description, in: D. Swern (Ed.), Organic Peroxides, Wiley-Interscience, New York, 1970, pp. $1-104$. 
[6] S. Di Tommaso, P. Rotureau, O. Crescenzi, C. Adamo, Oxidation mechanism of diethyl ether: a complex process for a simple molecule, Phys. Chem. Chem. Phys. 13 (2011) 14636-14645.

[7] R. Benassi, F. Taddei, Homolytic bond-dissociation in peroxides, peroxyacids, peroxyesters and related radicals: ab-initio MO calculations, Tetrahedron 50 (1994) 47954810.

[8] Y.-S. Duh, X. Hui Wu, C.-S. Kao, Hazard ratings for organic peroxides, Proc. Safety Prog. 27 (2008) 89-99.

[9] T.-C. Ho, Y.-S. Duh, J.R. Chen, Case studies of incidents in runaway reactions and emergency relief, Proc. Safety Prog. 17 (1998) 259-262.

[10] J.M. Hsu, M.S. Su, C.Y. Huang, Y.S. Duh, Calorimetric studies and lessons on fires and explosions of a chemical plant producing CHP and DCPO, J. Hazard. Mater. 217-218 (2012) 19-28.

[11] http://www.arkema-inc.com (accessed January 2014)

[12] http://www.plasticsindustry.org (accessed January 2014) and the information from the OPPSD - Organic Peroxide Producers Safety Division; and especially "Safety and handling of Organic Peroxides”: a guide prepared by the Organic Peroxide Producers Safety Division of the Society of the Plastics Industry, Inc, OPPSD bulletin AS-109, 2012 edition.

[13] Recommendations on the Transport of Dangerous Goods: Model Regulations, ST/SG/AC.10/1/Rev.17, vol 1, United Nations, New York/Geneva, 2011.

[14] Globally Harmonized System of classification and labelling of chemicals (GHS), ST/SG/AC.10/30/Rev.4, United Nations, New York/Geneva, 2011.

[15] R.H. Chang, J.M. Tseng, J.M. Jehng, C.M. Shu, H.Y. Hou, Thermokinetic model simulations for methyl ethyl ketone peroxide contaminated with $\mathrm{H}_{2} \mathrm{SO}_{4}$ or $\mathrm{NaOH}$ by DSC and VSP2, J. Therm. Anal. Calorim. 83 (2006) 57-62.

[16] L.-C. Tsai, M.-L. You, M.-F. Ding, C.-M. Shu, Thermal hazard evaluation of lauroyl peroxide mixed with nitric acid, Molecules 17 (2012) 8056-8067.

[17] EC Regulation $N^{\circ} 1907 / 2006$ of the European Parliament and of the Council of 18 December 2006 concerning the registration, evaluation, authorisation and restriction of chemicals (REACH). EC, Brussels, (2006).

[18] http://echa.europa.eu (accessed January 2014)

[19] ECHA, Guidance on information requirements and chemical safety assessment Chapter R.7a: Endpoint specific guidance, 2008. 
[20] ECHA, Guidance on information requirements and Chemical Safety Assessment Chapter R.7a :Endpoint specific guidance, version 2.1, 2013.

[21] Recommendations on the Transport of Dangerous Goods: Manual of Tests and criteria, ST/SG/AC.10/11/Rev.5, United Nations, New York/Geneva, 2011.

[22] T. Ando, Y. Fujimoto, S. Morisaki, Analysis of differential scanning calorimetric data for reactive chemicals, J. Hazard. Mater. 28 (1991) 251-280.

[23] ASTM E537-02, Standard Test Method for the Thermal Stability of Chemicals by Differential Scanning Calorimetry.

[24] ASTM Computer Program for Chemical Thermodynamic and Energy Release Evaluation - CHETAH; http://www.astm.org (accessed January 2014)

[25] V. K. Mohan, K. R. Becker, J. E. Hay, Hazard evaluation of organic peroxides, J. Hazard. Mater. 5 (1982), 197-220.

[26] Y. Sato, M. Akiyoshi, A. Miyake, T. Matsunaga, Prediction of explosibility of selfreactive materials by calorimetry of a laboratory scale and thermochemical calculations, Sci. Tech. Energ. Mater. 72(4) (2011), 97-107.

[27] A. Lewis, N. Kazantzis, I. Fishtik, J. Wilcox, Integrating process safety with molecular modeling-based risk assessment of chemicals within the REACH regulatory framework: Benefits and future challenges, J. Hazard. Mater. 142 (2007) 592-602.

[28] A. Tropsha, Best Practices for QSAR Model Development, Validation, and Exploitation, Mol. Inf. 29 (2010) 476-488.

[29] J. Dearden, A. Worth, In Silico Prediction of Physicochemical Properties: European Commission, Joint Research Centre (2007).

[30] A. R. Katritzky, M. Kuanar, S. Slavov, C. D. Hall, M. Karelson, I. Kahn, D.A. Dobchev, Quantitative Correlation of Physical and Chemical Properties with Chemical Structure: Utility for Prediction. Chem. Rev. 110 (2010) 5714-5789.

[31] G. Patlewicz, M. W. Chen, C. A. Bellin, Non-testing approaches under REACH - help or hindrance?Perspectives from a practitioner within industry, SAR QSAR Environ. Res. 22 (2011) 67-88.

[32] OECD, Guidance document on the validation of (Quantitative) Structure-Activity Relationships [(Q)SAR] models, Paris, 2007.

[33] F.A. Quintero, S.J. Patel, F. Muñoz, M. Sam Mannan, Review of Existing QSAR/QSPR Models Developed for Properties Used in Hazardous Chemicals Classification System, Ind. Eng. Chem. Res. 51 (2012) 16101-16115. 
[34] J.C. Dearden, P. Rotureau, G. Fayet, QSPR prediction of physico-chemical properties for REACH, SAR QSAR Environ. Res. 24(4) (2013) 545-584.

[35] G. Fayet, P. Rotureau, L. Joubert, C. Adamo, On the prediction of thermal stability of nitroaromatic compounds using quantum chemical calculations, J. Hazard. Mater. 171 (2009) 845-850.

[36] G. Fayet, P. Rotureau, L. Joubert, C. Adamo, Development of a QSPR model for predicting thermal stabilities of nitroaromatic compounds taking into account their decomposition mechanisms, J. Mol. Model. 17 (2010) 2443-2453.

[37] G. Fayet, P. Rotureau, C. Adamo, On the development of QSPR models for regulatory frameworks: the heat of decomposition of nitroaromatics as a test case, J. Loss Prev. Process Ind. 26 (2013) 1100-1105.

[38] P. Sang, J.-W. Zou, L. Xu, Y.-H. Liu, QSPR of Thermal Stability of Nitroaromatic Explosives using Theoretical Descriptors Derived from Electrostatic Potentials on the Molecular Surface, Chin. J. Struct. Chem. 30 (2011) 533-537.

[39] P. Sang, J. Zou, L. Xu, P. Zhou, Linear and Nonlinear QSPR Models for Predicting Thermal Stabilities of Nitroaromatic Compounds, Chem. Res. Chinese U. 27 (2011) 891-895.

[40] T. Atalar, S. Zeman, A New View of Relationships of the N-N Bond Dissociation Energies of Cyclic Nitramines. Part I. Relationships with Heats of Fusion, J. Energy Mater. 27 (2009) 186-199.

[41] M.H. Keshavarz, Predicting heats of fusion of nitramines, Indian J. Eng. Mater. Sci. 14 (2007) 386-390.

[42] S. Zeman, Some predictions in the field of the physical thermal stability of nitramines, Thermochim. Acta. 302 (1997) 11-16.

[43] F. Gharagheizi, M. Sattari, P. Ilani-Kashkouli, A.H. Mohammadi, D. Ramjugernath, D. Richon, Quantitative structure-property relationship for thermal decomposition temperature of ionic liquids, Chem. Eng. Sci. 84 (2012) 557-563.

[44] X. Yu, Z. Xie, B. Yi, X. Wang, F. Liu, Prediction of the thermal decomposition property of polymers using quantum chemical descriptors, Eur. Polym. J. 43 (2007) 818-823.

[45] Y. Lu, D. Ng, M.S. Mannan, Prediction of the Reactivity Hazards for Organic Peroxides Using the QSPR Approach, Ind. Eng. Chem. Res. 50 (2011) 1515-1522.

[46] G. Fayet, L. Joubert, P. Rotureau, C. Adamo, On the use of descriptors arising from the conceptual density functional theory for the prediction of chemicals explosibility, Chem. Phys. Lett. 467 (2009) 407-411. 
[47] G. Fayet, A. Del Rio, P. Rotureau, L. Joubert, C. Adamo, Predicting the thermal stability of nitroaromatic compounds using chemoinformatic tools, Mol. Inf. 30 (2011) 623634.

[48] V. Prana, G. Fayet, P. Rotureau, C. Adamo, Predictive QSPR models for impact sensitivity of nitroaliphatic compounds. J. Hazard. Mater. 235-236 (2012) 169-177.

[49] N.A. Milas, A. Golubović, Studies in Organic Peroxides. XXV. Preparation, Separation and Identification of Peroxides Derived from Methyl Ethyl Ketone and Hydrogen Peroxide, J. Am. Chem. Soc. 81 (1959) 5824-5826.

[50] Scigress, Fujitsu, 2008.

[51] H. Goto, E. Osawa, Corner flapping - a simple and fast algorithm for exhaustive generation of ring conformations, J. Am. Chem. Soc. 111 (1989) 8950-8951.

[52] H. Goto, E. Osawa, An efficient algorithm for searching low-energy conformers of cyclic and acyclic molecules, J. Chem. Soc. Perkin Trans. 2. (1993) 187-198.

[53] N. L. Allinger, Y.H. Yuh, J.H. Lii, Molecular mechanics. The MM3 force field for hydrocarbons. 1, J. Am. Chem. Soc. 111 (1989) 8551-8566.

[54] M. J. Frisch, G. W. Trucks, H. B. Schlegel, G. E. Scuseria, M. A. Robb, J. R. Cheeseman, J. A. Montgomery, Jr., T. Vreven, K. N. Kudin, J. C. Burant, J. M. Millam, S. S. Iyengar, J. Tomasi, V. Barone, B. Mennucci, M. Cossi, G. Scalmani, N. Rega, G. A. Petersson, H. Nakatsuji, M. Hada, M. Ehara, K. Toyota, R. Fukuda, J. Hasegawa, M. Ishida, T. Nakajima, Y. Honda, O. Kitao, H. Nakai, M. Klene, X. Li, J. E. Knox, H. P. Hratchian, J. B. Cross, V. Bakken, C. Adamo, J. Jaramillo, R. Gomperts, R. E. Stratmann,O. Yazyev, A. J. Austin, R. Cammi, C. Pomelli, J. W. Ochterski, P. Y. Ayala, K. Morokuma, G. A. Voth, P. Salvador, J. J. Dannenberg,V. G. Zakrzewski, S. Dapprich, A. D. Daniels, M. C. Strain, O. Farkas, D. K. Malick, A. D. Rabuck, K. Raghavachari, J. B. Foresman, J. V. Ortiz, Q. Cui, A. G. Baboul, S. Clifford, J. Cioslowski, B. B. Stefanov, G. Liu, A. Liashenko, P. Piskorz, I. Komaromi,R. L. Martin, D. J. Fox, T. Keith, M. A. Al-Laham, C. Y. Peng, A. Nanayakkara, M. Challacombe, P. M. W. Gill, B. Johnson, W. Chen, M. W. Wong, C. Gonzalez, J. A. Pople, Gaussian09, Gaussian, Inc., Wallingford CT, 2009.

[55] C. Adamo, V. Barone, Toward reliable density functional methods without adjustable parameters: The PBE0 model, J. Chem. Phys. 110 (1999) 6158-6170.

[56] R. Todeschini, Handbook of molecular descriptors, Wiley-VCH, Weinheim, New York, 2000. 
[57] M. Karelson, Molecular Descriptors in QSAR/QSPR, Wiley, New York, 2000.

[58] CodessaPro, University of Florida, 2002.

[59] M. J. Kamlet, The relationship of impact sensitivity with structure of organic high explosives. I Polynitroaliphatic explosives, Sixth Symposium (International) on Detonation, Coronado, California, 1976, pp. 312-322.

[60] R. Benassi, U. Folli, S. Sbardellati, F. Taddei, Conformational properties and homolytic bond cleavage of organic peroxides. I. An empirical approach based upon molecular mechanics and ab initio calculations, J. Comput. Chem. 4 (1993) 379-391.

[61] H. Chermette, Chemical reactivity indexes in density functional theory, J. Comput. Chem. 20 (1999) 129-154.

[62] P. Geerlings, F. De Proft, W. Langenaeker, Conceptual density functional theory, Chem. Rev. 103 (2003) 1793-1873.

[63] K. Fukui, T. Yonezawa, H. Shingu, A Molecular Orbital Theory of Reactivity in Aromatic Hydrocarbons, J. Chem. Phys. 20 (1952) 722-725.

[64] P. Gramatica, Principles of QSAR models validation: internal and external, QSAR Comb. Sci. 26 (2007) 694-701.

[65] A. Tropsha, Best Practices for QSAR Model Development, Validation, and Exploitation, Mol. Inf. 29 (2010) 476-488.

[66] F. Lindgren, B. Hansen, W. Karcher, M. Sjöström, L. Eriksson, Model validation by permutation tests: Applications to variable selection, J. Chemometr. 10 (1996) 521-532.

[67] C. Rücker, G. Rücker, M. Meringer, Y-Randomization and Its Variants in QSPR/QSAR, J. Chem. Inf. Model. 47 (2007) 2345-2357.

[68] A. Tropsha, P. Gramatica, V. K. Gombar, The importance of being earnest: Validation is the absolute essential for successful application and interpretation of QSPR models, QSAR Comb. Sci. 22 (2003) 69-77.

[69] G. Schüürmann, R.-U. Ebert, J. Chen, B. Wang, R. Kühne, External Validation and Prediction Employing the Predictive Squared Correlation Coefficient - Test Set Activity Mean vs Training Set Activity Mean, J. Chem. Inf. Model. 48 (2008) 2140-2145.

[70] V. Consonni, D. Ballabio, R. Todeschini, Comments on the Definition of the $\mathrm{Q}^{2}$ Parameter for QSAR Validation, J. Chem. Inf. Model. 49 (2009) 1669-1678.

[71] L.I.-K. Lin, A Concordance Correlation Coefficient to Evaluate Reproducibility, Biometrics. 45 (1989) 255-268.

[72] L.I.-K. Lin, Assay Validation Using the Concordance Correlation Coefficient, Biometrics. 48 (1992) 599-604. 
[73] J. Jaworska, N. Nikolova-Jeliazka, T. Aldenberg, QSAR Applicability Domain Estimation by Projection of the Training Set Descriptor Space: a Review. Altern. Lab. Anim. 33 (2005), 445-459.

[74] S. Weaver, M.P. Gleeson, The importance of the Domain of Applicability in QSAR Modeling, J. Mol. Graphics Model. 26 (2008), 1315-1326.

[75] N. Jeliazkova, J. Jaworska, Ambit Discovery, 2007.

[76] L.B. Kier, A Shape Index from Molecular Graphs, Quant. Struct.-Act. Relat. 4 (1985) 109-116. 
Figure 1. Example of a DSC curve. Case of tert-butyl peroxy-2-ethylhexanoate (CAS 300682-4)

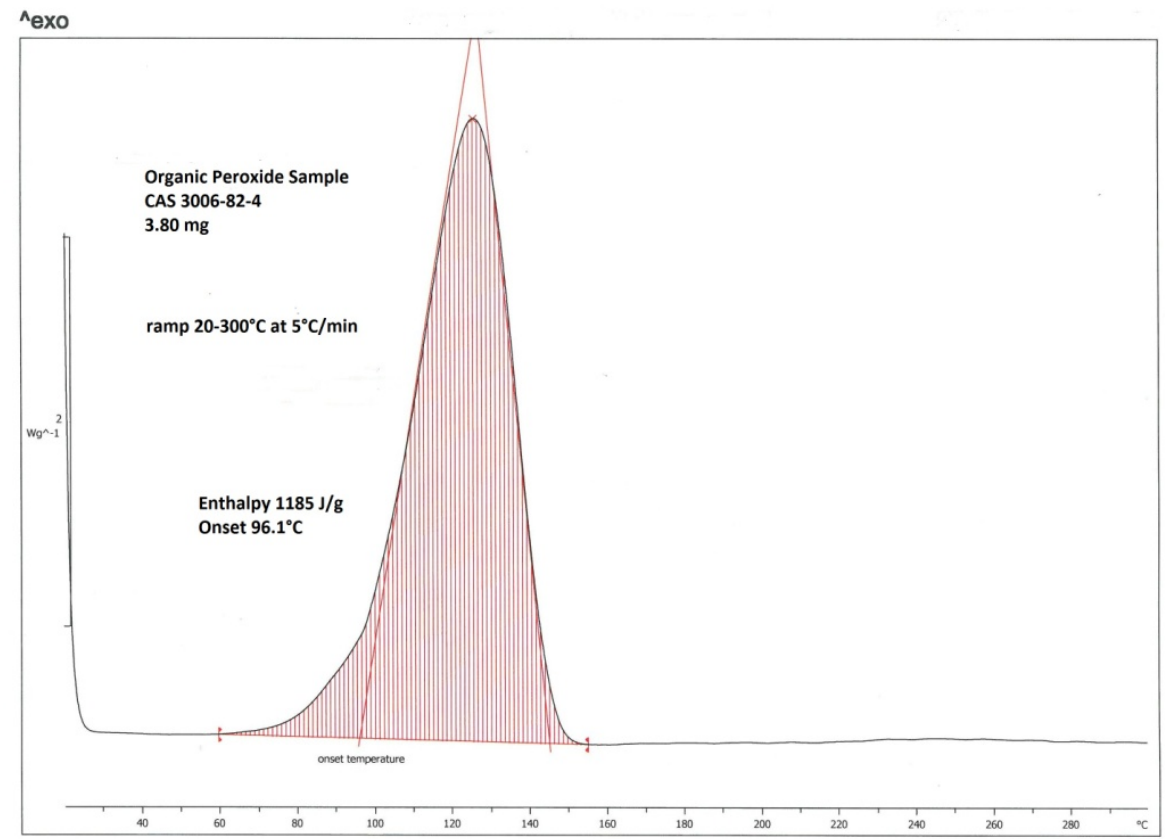

Figure 2. Evolution of decomposition heat measured as a function of concentration.

Sample 1: tert-butyl peroxypivalate (CAS 927-07-1); sample 2: di-tert-butyl peroxide (CAS 110-05-4); sample 3: tert-butyl peroxy-2-ethylhexanoate (CAS 3006-82-4)

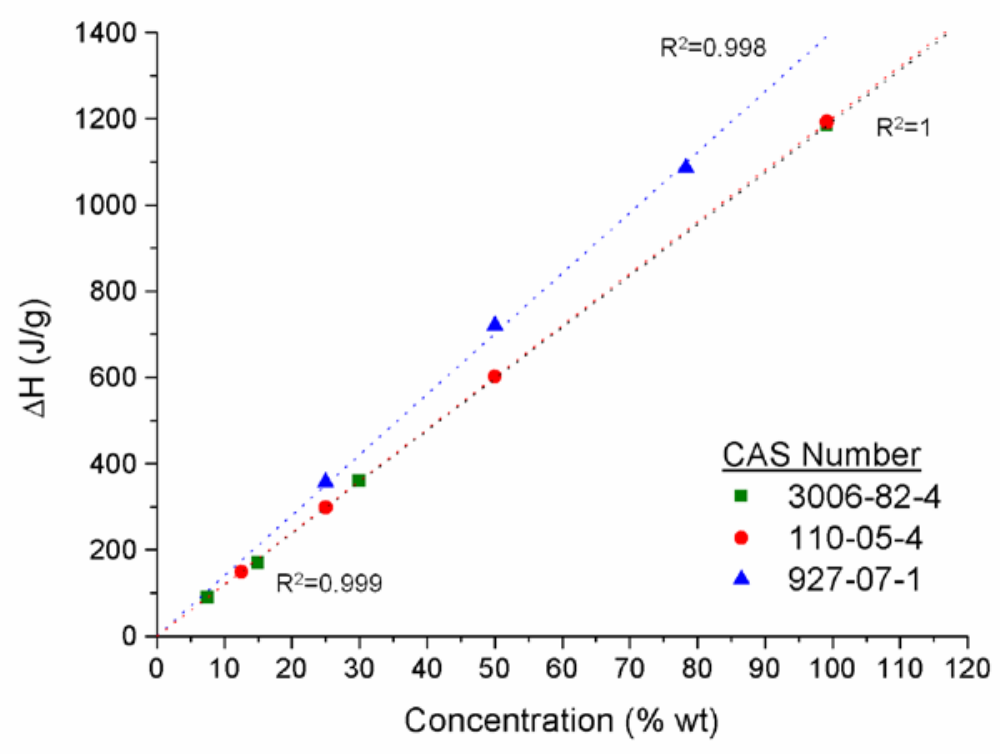

Figure 3. Experimental vs. predicted values of the decomposition heat divided by the concentration $(\Delta \mathrm{H} / \mathrm{C})$ 


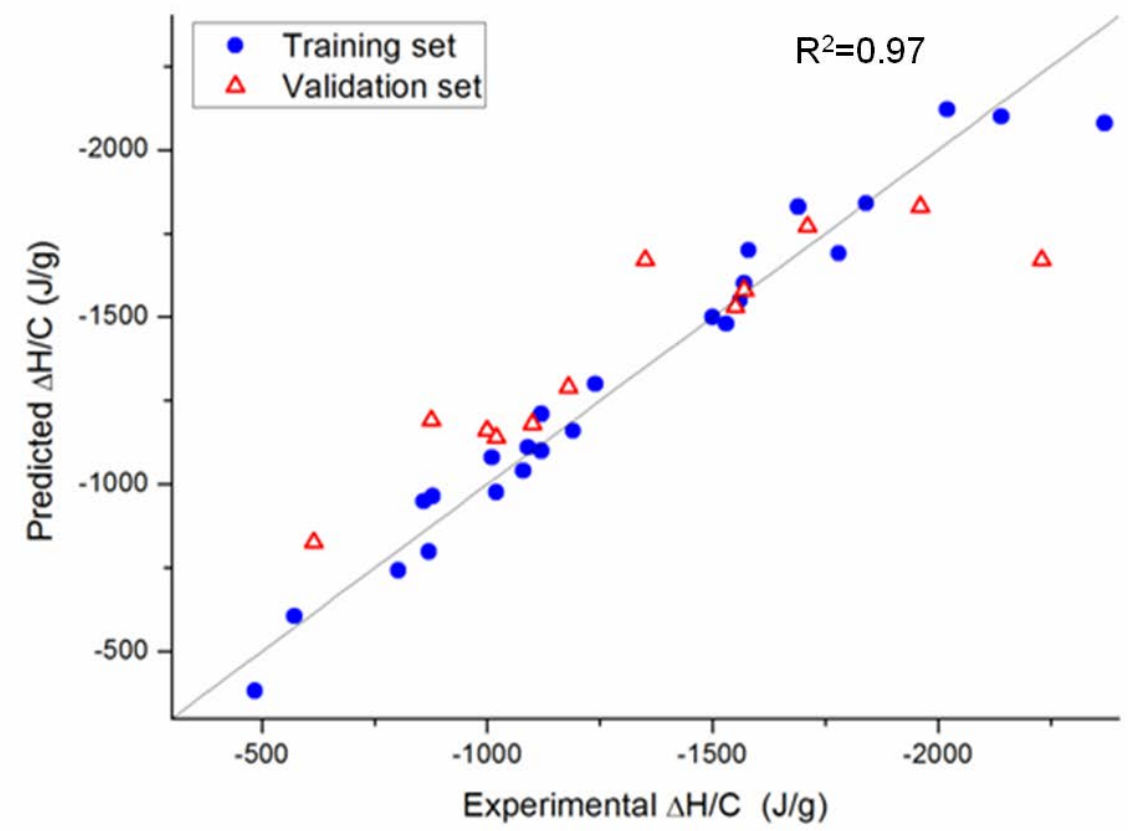

Figure 4. Correlation of the models issued from Y-randomization $\left(\mathrm{R}^{2}\right.$ random $)$ vs. level of randomization, as estimated by the correlation between the randomized and actual experimental values $\left(\mathrm{R}^{2}\left(\mathrm{Y}_{\text {random }} / \mathrm{Y}_{\exp }\right)\right)$

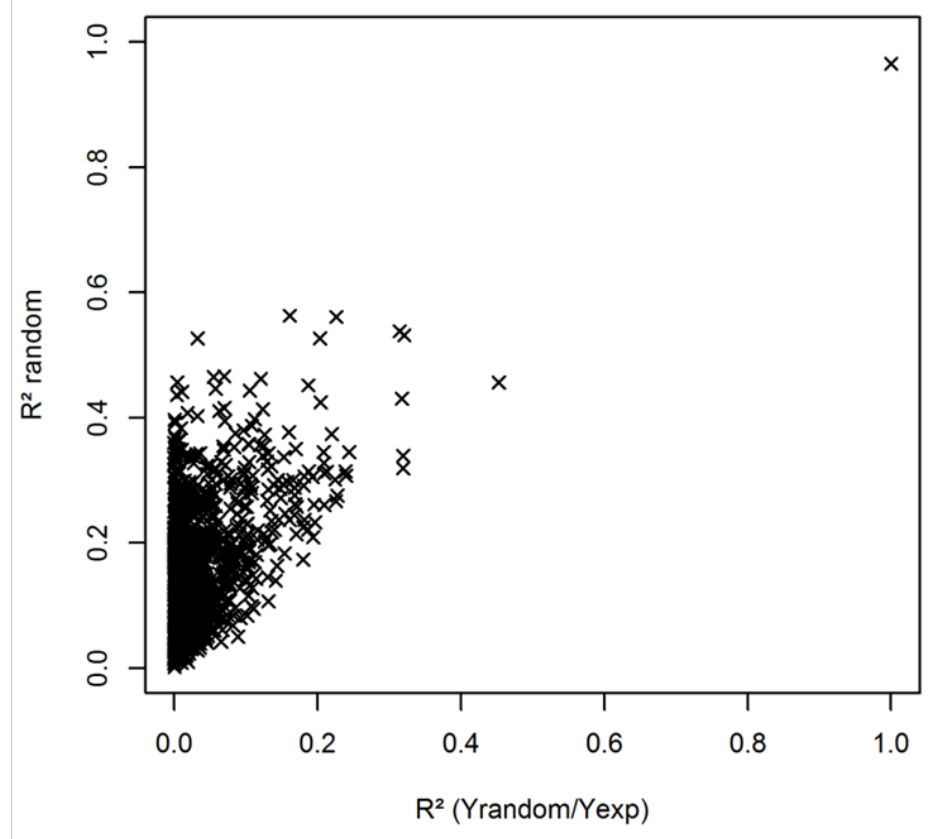

Figure 5. Experimental vs. predicted values of the onset temperature (Tonset) 


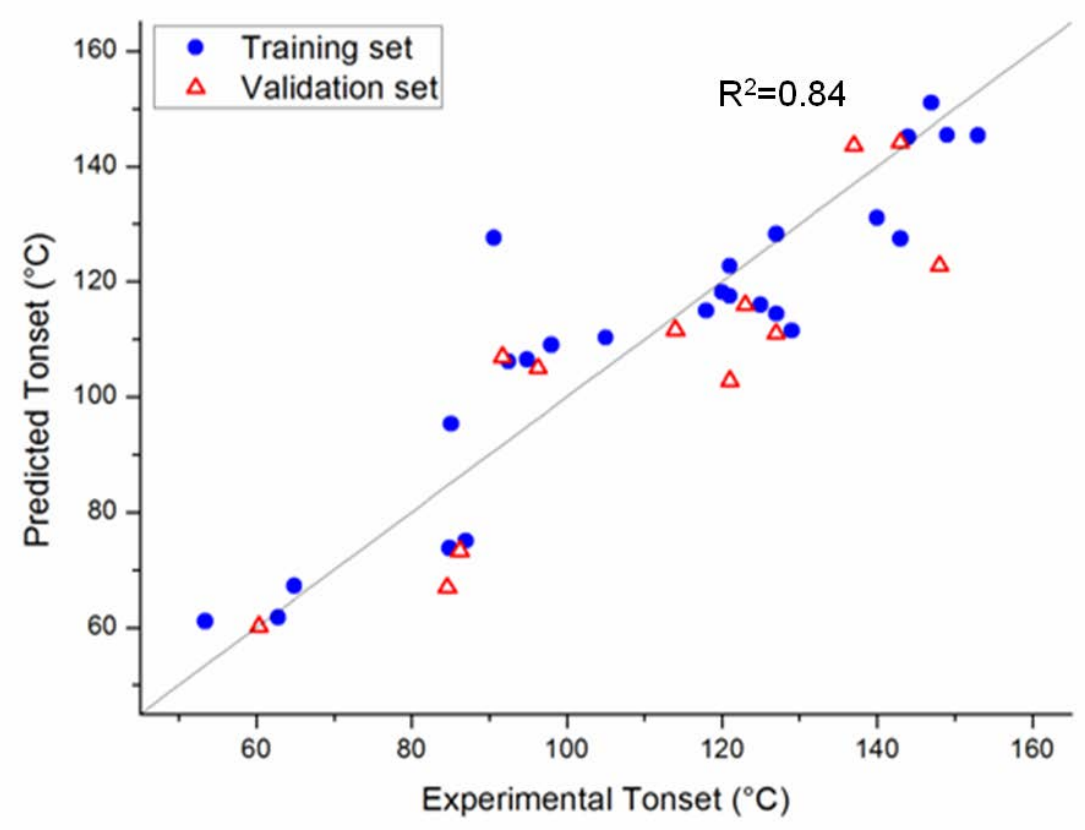


Table 1: Families of organic peroxides

\begin{tabular}{|c|c|}
\hline Kind of organic peroxides & General formula \\
\hline Dialkyl peroxides & $\mathrm{R}_{1}-\mathrm{O}-\mathrm{O}-\mathrm{R}_{2}$ \\
\hline Diacyl peroxides & 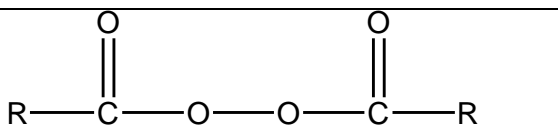 \\
\hline Hydroperoxides & $\mathrm{R}-\mathrm{O}-\mathrm{OH}$ \\
\hline Peroxyacids & $\|_{\mathrm{C}}^{\mathrm{O}}-\mathrm{OOH}$ \\
\hline Peroxyesters & $\|_{\mathrm{C}}^{\mathrm{O}}-\mathrm{O}-\mathrm{O}-\mathrm{R}_{2}$ \\
\hline Peroxyketals & 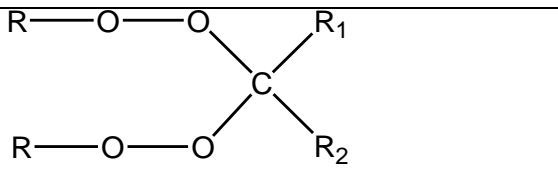 \\
\hline Peroxycarbonates and peroxydicarbonates & $\mathrm{R}-\mathrm{O}-\mathrm{C}-\mathrm{O}-\mathrm{O}-\mathrm{C}-\mathrm{O}-\mathrm{O}$ \\
\hline Ketone peroxides & $\mathrm{HO}-\mathrm{O}-\left.\right|_{\mathrm{R}_{2}} ^{\mathrm{R}_{2}}-\mathrm{O}-\mathrm{OH}$ \\
\hline
\end{tabular}


Table 2: Experimental and predicted values for the decomposition heat (J/g). Highlighted values are molecules of the validation set. Concentration is expressed in gram of organic peroxide by gram of sample.

\begin{tabular}{|c|c|c|c|c|c|}
\hline $\mathbf{N}^{\circ}$ & Name & Conc. & $\Delta \mathbf{H}_{\exp }$ & $\Delta \mathbf{H} / \mathbf{C}_{\exp }$ & $\begin{array}{c}\Delta H / C_{\text {pre }} \\
\text { d }\end{array}$ \\
\hline 1 & Dibenzoyl peroxide & 0.744 & -1170 & -1573 & -1579 \\
\hline 2 & Tert-butyl peroxy-3,5,5-trimethylhexanoate & 0.992 & -869 & -876 & -1186 \\
\hline 3 & Dicumyl peroxide & 0.994 & -866 & -871 & -798 \\
\hline 4 & Tert-butyl peroxy-2-ethylhexanoate & 0.992 & -1185 & -1194 & -1164 \\
\hline 5 & Tert-butyl peroxy-2-ethylhexylcarbonate & 0.975 & -1096 & -1124 & -1208 \\
\hline 6 & 2,5-dimethyl-2,5-di(tert-butylperoxy)hexane & 0.989 & -1334 & -1349 & -1669 \\
\hline 7 & Tert-butyl peroxypivalate & 0.752 & -1150 & -1529 & -1482 \\
\hline 8 & Di-(2-ethylhexyl) peroxydicarbonate & 0.99 & -1003 & -1013 & -1084 \\
\hline 9 & Tert-amyl peroxy-2-ethylhexanoate & 0.975 & -1067 & -1094 & -1111 \\
\hline 10 & Di-tert-butyl peroxide & 0.992 & -1175 & -1185 & -1289 \\
\hline 11 & Di-tert-amyl peroxide & 0.984 & -1086 & -1104 & -1181 \\
\hline 12 & Dilauroyl peroxide & 0.99 & -795 & -803 & -743 \\
\hline 13 & Tert-butyl peroxybenzoate & 0.986 & -1528 & -1550 & -1532 \\
\hline 14 & Tert-amyl hydroperoxide & 0.841 & -1993 & -2370 & -2081 \\
\hline 15 & Tert-butyl hydroperoxide & 0.685 & -1386 & -2024 & -2124 \\
\hline 16 & Tert-butyl cumyl peroxide & 0.955 & -1027 & -1076 & -1036 \\
\hline 17 & 2,5-dimethyl-2,5-dihydroperoxyhexane* & 0.736 & -2622 & -3562 & n.a. \\
\hline 18 & 1,1-di-(tert-butylperoxy)-3,3,5-trimethylcyclohexane & 0.958 & -1504 & -1570 & -1597 \\
\hline 19 & 1,1-di-(tert-butyl peroxy) cyclohexane & 0.504 & -989 & -1962 & -1828 \\
\hline 20 & Tert-amyl peroxy-2-ethylhexyl carbonate & 0.971 & -975 & -1004 & -1159 \\
\hline 21 & Ethyl-3,3-di-(tert-amyl peroxy) butyrate & 0.65 & -1027 & -1580 & -1696 \\
\hline 22 & Tert-amyl peroxy-3,5,5-trimethylhexanoate & 0.965 & -981 & -1017 & -1141 \\
\hline 23 & Tert-butyl peroxyisopropylcarbonate & 0.75 & -1124 & -1499 & -1500 \\
\hline 24 & Di-n-propyl peroxydicarbonate & 0.99 & -1824 & -1842 & -1844 \\
\hline 25 & Di-(3,5,5-trimethylhexanoyl) peroxide & 0.755 & -767 & -1016 & -976 \\
\hline 26 & Didecanoyl peroxide & 0.991 & -871 & -879 & -964 \\
\hline 27 & 2,2-di-(tert-butyl peroxy) butane & 0.496 & -1060 & -2138 & -2103 \\
\hline 28 & $\begin{array}{l}\text { 2,5-dimethyl-2,5-di-(2-ethylhexanoyl } \\
\text { hexane }\end{array}$ & 0.977 & -1092 & -1118 & -1095 \\
\hline 29 & 1,1-di-(tert-amyl peroxy) cyclohexane & 0.602 & -1029 & -1709 & -1767 \\
\hline 30 & Tert-butyl peracetate & 0.477 & -1066 & -2234 & -1672 \\
\hline 31 & 2,5-di(tert-butylperoxy)-2,5-dimethyl-3-hexyne & 0.471 & -837 & -1777 & -1692 \\
\hline 32 & Di-(4-tert-butylcyclohexyl) peroxydicarbonate & 0.952 & -586 & -615 & -826 \\
\hline 33 & Dicetyl peroxydicarbonate & 0.911 & -441 & -485 & -382 \\
\hline 34 & Dimyristyl peroxydicarbonate & 0.974 & -557 & -572 & -606 \\
\hline 35 & 1,1,3,3-tetramethylbutyl peroxy-2-ethylhexanoate & 0.908 & -834 & -919 & -950 \\
\hline 36 & Tert-butyl peroxydiethylacetate & 0.990 & -1225 & -1238 & -1305 \\
\hline 37 & 1,1,3,3-tetramethylbutyl hydroperoxide & 0.914 & -1545 & -1690 & -1830 \\
\hline 38 & 3,3,5,7,7-pentamethyl-1,2,4-trioxepane & 0.979 & -1523 & -1556 & -1547 \\
\hline
\end{tabular}


Table 3: Experimental and predicted values for the onset temperature of decomposition (Tonset, ${ }^{\circ} \mathrm{C}$ ). Highlighted values are molecules of the validation set.

\begin{tabular}{|c|c|c|c|}
\hline $\mathbf{N}^{\circ}$ & Name & experimental & prediction \\
\hline 1 & Dibenzoyl peroxide & 105 & 110 \\
\hline 2 & Tert-butyl peroxy-3,5,5-trimethylhexanoate & 114 & 112 \\
\hline 3 & Dicumyl peroxide & 143 & 144 \\
\hline 4 & Tert-butyl peroxy-2-ethylhexanoate & 96 & 105 \\
\hline 5 & Tert-butyl peroxy-2-ethylhexylcarbonate & 125 & 116 \\
\hline 6 & 2,5-dimethyl-2,5-di(tert-butylperoxy)hexane & 148 & 123 \\
\hline 7 & Tert-butyl peroxypivalate & 85 & 95 \\
\hline 8 & Di-(2-ethylhexyl) peroxydicarbonate & 65 & 67 \\
\hline 9 & Tert-amyl peroxy-2-ethylhexanoate & 98 & 109 \\
\hline 10 & Di-tert-butyl peroxide & 153 & 145 \\
\hline 11 & Di-tert-amyl peroxide & 149 & 145 \\
\hline 12 & Dilauroyl peroxide & 86 & 73 \\
\hline 13 & Tert-butyl peroxybenzoate & 121 & 103 \\
\hline 14 & Tert-amyl hydroperoxide & 143 & 127 \\
\hline 15 & Tert-butyl hydroperoxide & 91 & 128 \\
\hline 16 & Tert-butyl cumyl peroxide & 147 & 151 \\
\hline 17 & 2,5-dimethyl-2,5-dihydroperoxyhexane & 127 & 111 \\
\hline 18 & 1,1-di-(tert-butylperoxy)-3,3,5-trimethylcyclohexane & 120 & 118 \\
\hline 19 & 1,1-di-(tert-butyl peroxy) cyclohexane & 121 & 118 \\
\hline 20 & Tert-amyl peroxy-2-ethylhexyl carbonate & 123 & 116 \\
\hline 21 & Ethyl-3,3-di-(tert-amyl peroxy) butyrate & 140 & 131 \\
\hline 22 & Tert-amyl peroxy-3,5,5-trimethylhexanoate & 118 & 115 \\
\hline 23 & Tert-butyl peroxyisopropylcarbonate & 127 & 114 \\
\hline 24 & Di-n-propyl peroxydicarbonate & 53 & 61 \\
\hline 25 & Di-(3,5,5-trimethylhexanoyl) peroxide & 87 & 75 \\
\hline 26 & Didecanoyl peroxide & 88 & 74 \\
\hline 27 & 2,2-di-(tert-butyl peroxy) butane & 137 & 144 \\
\hline 28 & 2,5-dimethyl-2,5-di-(2-ethylhexanoyl peroxy) hexane & 95 & 106 \\
\hline 29 & 1,1-di-(tert-amyl peroxy) cyclohexane & 121 & 123 \\
\hline 30 & Tert-butyl peracetate & 129 & 111 \\
\hline 31 & 2,5-di(tert-butylperoxy)-2,5-dimethyl-3-hexyne & 144 & 145 \\
\hline 32 & Di-(4-tert-butylcyclohexyl) peroxydicarbonate & 85 & 67 \\
\hline 33 & Dicetyl peroxydicarbonate & 63 & 62 \\
\hline 34 & Dimyristyl peroxydicarbonate & 60 & 60 \\
\hline 35 & 1,1,3,3-tetramethylbutyl peroxy-2-ethylhexanoate & 92 & 107 \\
\hline 36 & Tert-butyl peroxydiethylacetate & 93 & 106 \\
\hline 37 & 1,1,3,3-tetramethylbutyl hydroperoxide & 127 & 128 \\
\hline 38 & 3,3,5,7,7-pentamethyl-1,2,4-trioxepane* & 180 & n.a. \\
\hline
\end{tabular}

*outlier 
Table 4: Performances of the new MLR models

\begin{tabular}{|c|c|c|c|}
\hline Property & $\Delta \mathbf{H}(\mathrm{J} / \mathrm{g})$ & $\begin{array}{c}\Delta H / C \\
(\mathrm{~J} / \mathrm{g})\end{array}$ & $\begin{array}{c}\text { Tonset } \\
\left({ }^{\circ} \mathrm{C}\right)\end{array}$ \\
\hline $\begin{array}{l}\text { Number of } \\
\text { descriptors }\end{array}$ & 4 & 4 & 3 \\
\hline $\mathrm{R}^{2}$ & 0.90 & 0.97 & 0.84 \\
\hline RMSE & 113 & 99 & 12 \\
\hline MAE & 71 & 67 & 9 \\
\hline $\mathrm{Q}^{2}$ & 0.83 & 0.94 & 0.77 \\
\hline $\mathrm{Q}^{2} \mathrm{ccv}_{\mathrm{c}}$ & 0.85 & 0.95 & 0.68 \\
\hline $\mathrm{Q}^{2}{ }_{10 \mathrm{cv}}$ & 0.82 & 0.94 & 0.78 \\
\hline $\mathrm{Q}^{2} 7 \mathrm{cv}$ & 0.83 & 0.94 & 0.78 \\
\hline $\mathrm{R}^{2} \mathrm{YS}$ & 0.17 & 0.17 & 0.13 \\
\hline $\mathrm{SD}_{\mathrm{YS}}$ & 0.10 & 0.10 & 0.09 \\
\hline $\mathrm{R}^{2}{ }_{\mathrm{ext}}$ & 0.32 & 0.81 & 0.80 \\
\hline $\mathrm{RMSE}_{\mathrm{ext}}$ & 358 & 301 & 16 \\
\hline $\mathrm{MAE}_{\text {ext }}$ & 207 & 173 & 11 \\
\hline $\mathrm{Q}^{2} \mathrm{~F} 1$ & 0.24 & 0.74 & 0.74 \\
\hline $\mathrm{Q}^{2} \mathrm{~F} 2$ & 0.23 & 0.74 & 0.74 \\
\hline $\mathrm{Q}^{2} \mathrm{~F} 3$ & 0.28 & 0.77 & 0.78 \\
\hline CCC & 0.53 & 0.82 & 0.87 \\
\hline $\mathrm{R}^{2}$ in & 0.32 & 0.81 & 0.83 \\
\hline $\mathrm{RMSE}_{\text {in }}$ & 358 & 301 & 14 \\
\hline $\mathrm{MAE}_{\text {in }}$ & 207 & 173 & 10 \\
\hline $\mathrm{Q}^{2} \mathrm{~F}$ in & 0.24 & 0.74 & 0.78 \\
\hline $\mathrm{Q}^{2} \mathrm{~F}$ in & 0.23 & 0.74 & 0.78 \\
\hline $\mathrm{Q}^{2} \mathrm{~F}$ in & 0.28 & 0.77 & 0.83 \\
\hline $\mathrm{CCC}_{\text {in }}$ & 0.53 & 0.82 & 0.90 \\
\hline
\end{tabular}

